\title{
A palavra de Nelly Novaes Coelho
}

Cleide da Costa e Silva Papes ${ }^{1}$

(Fonte: acervo Nelly N. Coelho)

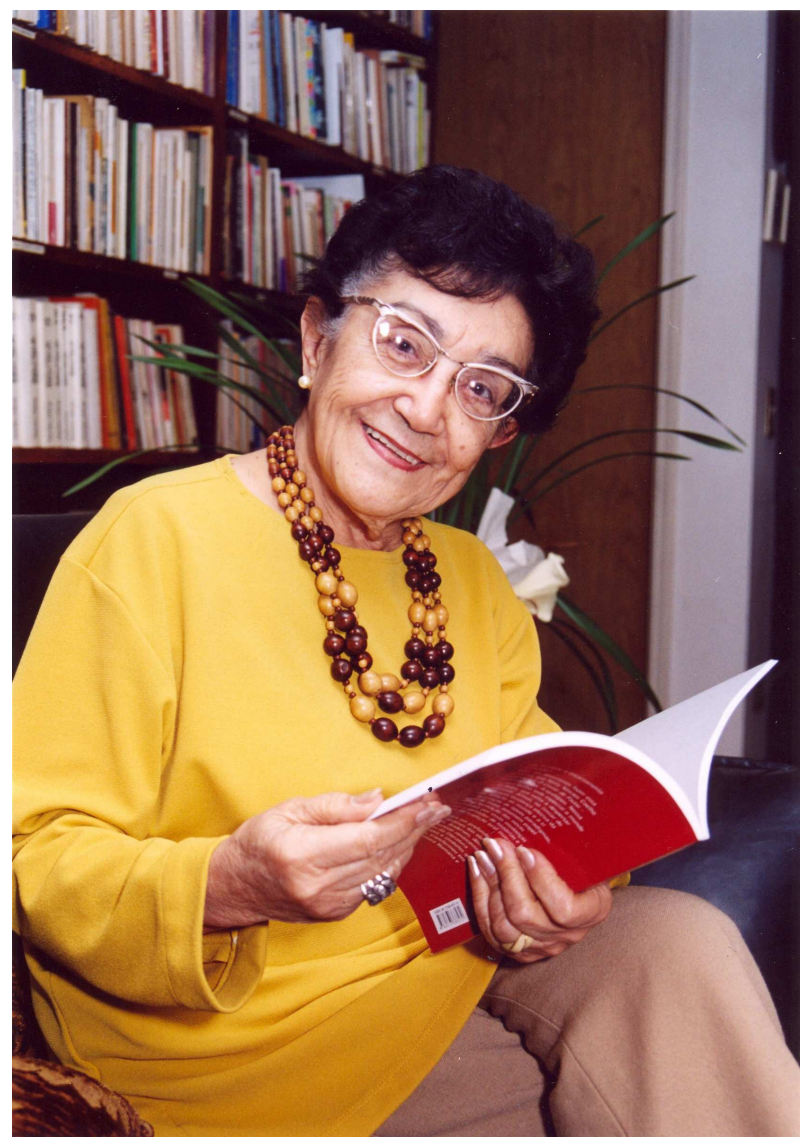

Ela entra e logo ilumina todo o ambiente. Em sintonia de reciprocidade e de valorização, traz consigo uma energia renovadora que conforta e anima a sempre planejar novos horizontes na vida. Seu otimismo em relação ao presente e ao futuro contagia e, com efeito, leva à crença de que o ser humano é capaz de mudar o mundo. Por essa razão, tem só palavras positivas a comunicar aos outros, enaltecendo as boas qualidades de cada pessoa em todas as circunstâncias de vivência e de criação.

Estar com Nelly Novaes Coelho é sempre uma preciosa oportunidade de aprendizado, quer pelo privilégio de ser seu aluno ou aluna nos bancos universitários, quer como ouvinte em seminários e eventos culturais ou simplesmente em conversas informais no dia-a-

${ }^{1}$ Doutora em Letras pela Universidade de São Paulo. 
dia. Na verdade, ensinar e com generosidade incondicional transmitir seus conhecimentos e suas descobertas teóricas e analíticas em Literatura tem sido o grande propósito de sua vida.

Dedicada à pesquisa e aos estudos nessa área, ela transforma a palavra literária em caminhos de orientação para o encontro eu-outro e a compreeensão do ser humano. Do universo poético e ficcional em que atua com uma proficua análise literária ingressa no plano da formação de alunos, pesquisadores e educadores de todos os níveis. Efetivamente, coloca em prática a sua convicção de que "a literatura é instrumento de conhecimento do mundo, do eu e do outro", como ela mesma afirma.

"Que é a literatura senão experiências humanas transformadas em linguagem?", pergunta a pesquisadora, e nesse questionamento marca o objetivo maior de todos os seus projetos, estudos e análise: a literatura como ponto de encontro entre um eu (o leitor) e a escrita de um outro (o escritor). Segundo ela, desse encontro virá a conscientização para o homem pós-moderno reconhecer-se como ser de linguagem e assumir a responsabibidade de renomear o mundo fragmentado e sem valores à sua volta.

Em toda a sua trajetória, como docente e profunda conhecedora do fenômeno literário, realça essa proposição, presente nas disciplinas ministradas na Universidade de São Paulo e em outras que teve a oportunidade de criar (Teoria Literária, Universidade Estadual de Marilia, 1961; Literatura Infantil/Juvenil, Universidade de São Paulo, 1980), presente nos projetos de pesquisa da pós-graduação (USP) e em toda a sua produção intelectual.

Ensaísta, crítica literária e especialista em Literatura Contemporânea (Brasil / Portugal) e em Literatura Infantil e Juvenil, Nelly Novaes Coelho é graduada em Letras Neolatinas (1959) pela Universidade de São Paulo e doutora em Letras (Literatura Portuguesa, 1964-1967) pela mesma universidade, cujo estudo e pesquisa estiveram sob a orientação do Prof. Dr. Antonio Soares Amora. Como bolsista da Fundação Calouste Gulbenkian realizou extensa pesquisa em Portugal sobre Aquilino Ribeiro e sua obra na elaboração da tese Jardim das 
Tormentas: Gênese da ficção de Aquilino Ribeiro, publicada pelas edições Quíron, em 1973. Nessa obra destaca-se o seu apurado olhar analitico sobre o texto literário, da mesma forma evidente em artigos e ensaios publicados no Suplemento Literário do jornal O Estado de São Paulo de que foi colaboradora por uma década (1961-1971).

Ao ingressar na graduação, já iniciada na leitura dos grandes clássicos da literatura nacional e estrangeira, aprofundou seus conhecimentos ao entrar em contato com a teoria de grandes pensadores que muito influenciaram na sua formação e na sua visãode-mundo, como Kant, Nietzsche, Maulraux, Spengler, Edgar Morin e outros.

A atividade docente na Faculdade de Filosofia Letras e Ciências Humanas da Universidade de São Paulo começou em 1961, como professora assistente nas áreas de Espanhol (1961) e de Literatura Portuguesa (1963). Nos anos da década seguinte, ofereceu cursos no exterior sobre Literatura Portuguesa (Universidade de Lisboa, 1971) e sobre Literatura e Cultura Brasileira em nível de pós-graduação (University of California/ Los Angeles, 1979, pela Fulbright Foundation - USA). Fora das universidades muitos cursos, palestras e mesasredondas em seminários de diversos congressos de literatura e outros eventos culturais puderam contar durante todos esses anos, desde o início de sua carreira, com a palavra dessa incansável estudiosa que abriu grandes perspectivas para muitas pessoas encontrarem o seu caminho de pesquisa, estudo e ação educativa através da literatura.

A força dessa palavra é ainda maior na sua produção intelectual, tornando perene e constante a possibilidade de se aprender pela luminosidade de sua lucidez a respeito do ser humano, do mundo e da vida em seus estudos e análise sobre literatura e especialmente sobre Literatura Infantil e Juvenil. Preocupada com o ensino e a formação de profissionais na educação das gerações mais novas, tem realizado diversos trabalhos na intenção de prepará-los para o ensino da literatura e a formação de leitores. 
Fazem parte desse objetivo O Ensino da Literatura (1966), Literatura e Linguagem (1974) e outra obra altamente significativa dentro dessa linha - Literatura Infantil - Teoria, análise, didática (1981), leitura básica para alunos universitários, pesquisadores e educadores em busca de conhecimentos e orientações nessa área, com fundamentos teóricos imprescindiveis para os estudos literários. Apresentando as origens da Literatura Infantil, essa obra trata da forma e da matéria da literatura, caminhando da teoria à análise do texto ao mesmo tempo que estabelece as categorias do leitor no processo de desenvolvimento do ser.

Com Dicionário Crítico da Literatura Infantil/Juvenil (1983) e Panorama Histórico da Literatura Infantil/Juvenil (1984), Nelly Novaes Coelho amplia o estudo e a análise literária nesse campo e marca claramente a íntima ligação que existe entre Literatura, História e Educação. Ao tomar Monteiro Lobato como marco divisório, essa obra apresenta um painel de autores brasileiros, dos precursores no século XIX e primórdios da literatura infantil no Brasil (1808-1920) ao período lobatiano e pós-lobatiano (1920-1990). Panorama Histórico da Literatura Infantil/Juvenil descreve o percurso histórico e estético da criação para crianças e jovens, das origens indo-europeias da literatura ocidental ao Brasil contemporâneo.

Tais trabalhos são de fundamental importância para a pesquisa e os estudos literários realizados na graduação e pós-graduação da FFLCH da Universidade de São Paulo onde ela criou a disciplina Literatura Infantil e Juvenil (Brasil e Portugal), cujos objetivos estenderam-se depois a muitas outras universidades, a outras áreas do conhecimento, a escolas do ensino infantil e fundamental na tarefa de formação do ser e do leitor.

Em O Conto de Fadas - simbolos, mitos, arquétipos (1987) a palavra de Nelly Novaes Coelho ganha dimensão poética no tratamento teórico de uma das mais expressivas formas da literatura infantil (o conto de fadas), pela qual abre um amplo horizonte de se poder reencantar as crianças e os jovens em um mundo onde não mais se 
permite idealizar e sonhar. Segundo a autora declara nesse livro, a "pesquisa sobre o conto de fadas teve sempre, como alvo maior, a Educação e sua relação com a Literatura" com um importante compromisso a cumprir: formar "o novo tipo de homem que estaria sendo engendrado no seio da Sociedade Cibernética". Abordando apenas uma forma literária, mais uma vez ela aponta a literatura como meio de recuperação do ser, considerando-a como um "antídoto à robotização que retira o homem de sua essência e de sua atuação como ser de linguagem".

Nos primeiros estudos sobre literatura contemporânea na década de 1960, como colaboradora do Suplemento Literário do jornal O Estado de São Paulo, Nelly Novaes Coelho volta-se para um importante veio na sua análise crítica: a produção literária feminina que se tornará um dos eixos essenciais de sua produção intelectual e de seus projetos na ação docente. Artigos e ensaios publicados em jornais e revistas especializados ou preparados para cursos de especialização em congressos sobre mulher e literatura feminina antecederam e depois fizeram parte de uma extensa abordagem crítica na sua obra, concretizada em A Literatura Feminina no Brasil Contemporâneo (1993) e Dicionário Crítico de Escritoras Brasileiras (2003). Em ambos a pesquisadora reitera, na literatura, a Palavra da Mulher no processo de reconstrução do mundo e revela o enigma do Grande Feminino na criação da geratriz e nutriz de um novo tempo.

Abrangendo a obra de muitos autores do Brasil e Portugal, ainda fazem parte da produção de Nelly Novaes Coelho outros títulos, numerosos ensaios e artigos sobre prosa e poesia publicados em jornais e revistas no Brasil e no exterior, e muitos textos em capítulos, prefácio, posfácio e apresentações na obra de diversos autores brasileiros e portugueses.

Sob sua orientação na Universidade de São Paulo, as linhas de pesquisa que fundaram as disciplinas e os projetos da pós-graduação dentro da perspectiva de toda sua produção geraram inúmeros trabalhos acadêmicos, dissertações e teses de doutorado, significativos 
para o estudo da Literatura Contemporânea e da Literatura Infantil e Juvenil, propagando muitos outros projetos culturais e educativos além dos muros da universidade.

Atualmente, dedica-se ao estudo dos ficcionistas brasileiros do século XX, contemplando oitenta autores, desde Mário de Andrade. Segundo afirmação da própria estudiosa, os ensaios preparados para esse trabalho, Escritores Brasileiros - Século XX, apresentarão uma minuciosa biobibliografia e a análise de um dos romances de cada autor. Seu futuro projeto, já em germinação desde o início de sua atividade docente e intelectual, será produzir um trabalho sobre um currículo de ensino com base na literatura englobando todos os níveis de ensino, desde a Educação Infantil. Com propostas práticas de atividades e análise do texto literário (Literatura Infantil/Juvenil) e fundamentos teóricos para orientar o professor nos planos de curso, a autora marcará definitivamente a ligação entre Literatura, História e Educação, renovando o seu compromisso de orientar e auxiliar os professores a se tornarem agentes de transformação na reorganização dos valores do mundo atual.

Mesmo tendo se aposentado da Universidade de São Paulo em 1992, permanece ativa para cursos e orientação em nível de pósgraduação (mestrado e doutorado) como Professora Titular, credenciada nas áreas de Literatura Portuguesa e de Estudos Comparados de Literaturas de Lingua Portuguesa ou como examinadora em sucessivas bancas de qualificação e defesa na pós-graduação.

Felizmente, por vários caminhos a palavra de Nelly Novaes Coelho chegou a muitos lugares nos quatro cantos do Brasil e também a muitos outros no exterior, como Portugal onde há muito tempo é consagrada por sua análise crítica a respeito da obra de tantos autores, principalmente contemporâneos com quem teve ainda a oportunidade de conviver, entre eles Vergílio Ferreira, Fernando Namora, Augusto Abelaira, José Cardoso Pires, Agustina Bessa Luís, Ruben A.

Por sua extensa e profunda atuação intelectual e cultural no Brasil e em Portugal, é detentora de diversos prêmios, homenagens e 
distinções: Prêmio Bocage (1966), pelo Min. Educação Lisboa, ex.aequo Dra. Maria Helena da Rocha Pereira; Prêmio Jabuti/ Ensaio (1974), pela Câmara Brasileira do Livro; Prêmio/Ensaio (1975), pela Associação Paulista de Críticos de Arte; Prêmio Especial da Crítica -30 anos de crítica literária (1983), pela Associação Paulista de Crítica de Arte; Prêmio "Professor-Destaque" (1991), homenagem prestada pelo DD. Reitor Roberto Lobo e Silva, da Universidade de São Paulo; Prêmio Clara Ramos (1997), pela União Brasileira de Escritores, RJ; Título de Comendadora por mérito cultural (1998), pela Universidade Minhota Pólo Barcelos/Minho / Portugal; Prêmio Jaburu - Personalidade do ano (1998), pelo Conselho Estadual de Cultura do Governo de Goiás; Sala Nelly Novaes Coelho (2007), homenagem da Diretoria das Bibliotecas Públicas do Estado de São Paulo/ Secretaria de Cultura de São Paulo; entre outros.

Sempre atuante, pertence às seguintes associações: Instituto Histórico e Geográfico de São Paulo (2000); Association pour la Pensée Complexe. APC. Paris (1998); Associação Paulista de Críticos de ArteAPCA (Presidente/1990); Instituto Internacional Ibero-Americano/USA (1988); Associação Amigos da Biblioteca Mário de Andrade (1987); Membro-Correspondente: Academia Goiana de Letras (1987) e Academia Feminina de Letras e Artes de Goiás e Letras de Pernambuco (1984); Academia Paulista de História (1985); Clube de Poesia do Brasil (1984); Fulbright Alumini Association. Pennzilvania/USA (1979); União Brasileira de Escritores -UBE - S. Paulo (1974).

Grande modelo para todas as pessoas que passaram por suas aulas e sua orientação, Nelly Novaes Coelho deixa muitas lições e o valioso legado de que o ser humano pode superar as mais dificeis barreiras a partir do momento em que assumir o fato de que é uma possibilidade ilimitada de conhecimento e o efetivo renomeador de um novo mundo. Para ela, a nova utopia é o próprio homem, criador de si mesmo, de cuja palavra depende a inauguração de uma outra era. Ao buscar a revelação dessa palavra na Literatura, ela resgata fatos e circunstâncias que, ao longo do tempo, marcaram a inexorável 
caminhada do homem invariavelmente revestido dos mesmos sonhos, das mesmas esperanças e paixões. Na verdade, com a intenção de educar, insere-se ela própria na História, proporcionando novas formas de ver o mundo, o homem, a vida e acenando para um fazer que depende de cada um de nós dentro da sociedade em que nos encontramos.

\section{Bibliografia:}

Literatura Infantil - Teoria-Análise- Didática. 12. ed. 2009.

O Conto de fadas: Simbolos- Mitos- Arquétipos. 2008.

Primeiro Dicionário Escolar (1700 verbetes). 2008.

Panorama Histórico da Literatura Infantil/Juvenil. 2009 (no prelo).

Escritores Portugueses - Século XX. Imprensa Nac./Lisboa. 2007.

Dicionário Critico de Literatura Infantil/Juvenil Brasileira. 2007.

Dicionário Crítico de Escritoras Brasileiras. 2003.

Erotismo, Maldição, Misticismo (na obra de José A. Pinto). 2001.

Literatura: Arte, Conhecimento e Vida. 2000.

A Literatura Feminina no Brasil Contemporâneo. 1993.

Guimarães Rosa ( Col. Escritores de Hoje). 1975.

Linguagem e Literatura. 1974.

Aquilino Ribeiro ( Col. Escritores de Hoje). 1973.

Cassiano Ricardo (Col. Brasil Moço). 1972.

Lygia Fagundes Telles (Col. Brasil Moço). 1972.

Escritores Portugueses (Col. Logos). 1972.

Carlos Nejar e a Geração de 1960. 1971.

Mário de Andrade para a Nova Geração. 1970.

Três Momentos Poéticos (Cecília Meireles/Bocage/A. Nobre). 1970.

Ramalho Ortigão (Col. Nossos Clássicos). 1968.

O Ensino da Literatura. 1966.

Tempo, Solidão e Morte. 1964. 